\title{
Thermal Properties and Wetting Behavior of High Temperature Zn-Al-In Solders
}

\author{
Tomasz Gancarz, Janusz Pstruś, Przemysław Fima, and Sylwia Mosińska
}

(Submitted October 20, 2011; in revised form January 3, 2012)

\begin{abstract}
Solders for ultrahigh-temperature applications were defined by Vianco as those able to sustain working conditions with temperatures as high as $573 \mathrm{~K}$, with momentary temperature rise up to $623 \mathrm{~K}$. Zn-Al eutectic alloy (12 at.\% Al) fits such defined criteria with respect to its melting temperature. It was found that small additions of indium to $\mathrm{Zn}$-Al eutectic lower its melting temperature. The aim of this work is to assess if and to what extent thermal properties and wetting behavior are affected. It was found that addition of In increases electrical resistivity and coefficient of thermal expansion value. Wetting angles on $\mathrm{Cu}$ and $\mathrm{Al}$ substrates of liquid $\mathrm{Zn}$-Al eutectic-based alloys containing up to 1.5 at.\% of In were studied with the sessile drop method, after wetting at $773 \mathrm{~K}$ in the presence of flux. A decrease of apparent wetting angle was observed with increasing concentration of In. After wetting tests solidified alloy-substrate couples were crosssectioned and examined with scanning electron microscopy coupled with electron dispersive X-ray analysis.
\end{abstract}

Keywords microstructure, thermal properties, wetting, Zn-Al-In alloys

\section{Introduction}

Worldwide environment-protective legislation and following restrictions on the use of hazardous substances made replacement of $\mathrm{Pb}$-containing solders necessary. The RoHS directive banned the use of $\mathrm{Pb}$ in solder joints, and every few years expands to another group of materials, including materials for the supervision and control, and medical devices. Numerous lead-free solders studies have been conducted in recent years (Ref 1-5), and focused on the solders with a melting point below $473 \mathrm{~K}$, which can replace low-melting eutectic Sn-37Pb (wt.\%). As a $\mathrm{Pb}$-free replacement, Sn-based alloys such as: $\mathrm{Sn}-\mathrm{Ag}-\mathrm{Cu}$ and $\mathrm{Sn}-\mathrm{Zn}$, which have properties similar to the $\mathrm{Pb}-\mathrm{Sn}$ eutectic alloy, have been proposed. However, in the case of devices utilizing $\mathrm{Pb}$-based solders with melting point above $523 \mathrm{~K}$, the solder is used in various types of applications not only as die-attach solders but also for assembling optical components, automobile circuit boards, circuit modules for step soldering, aircraft, space satellite, automotive, oil and gas well

This article is an invited submission to JMEP selected from presentations at the Symposia "Wetting, soldering and brazing" and "Diffusion bonding and characterization" belonging to the Topic "Joining" at the European Congress and Exhibition on Advanced Materials and Processes (EUROMAT 2011), held September 12-15, 2011, in Montpellier, France, and has been expanded from the original presentation.

Tomasz Gancarz, Janusz Pstruś, and Przemysław Fima, Institute of Metallurgy and Materials Science, Polish Academy of Sciences, Krakow, Poland; and Sylwia Mosińska, Wroclaw University of Technology, Wroclaw, Poland. Contact e-mail: nmgancar@imim-pan. krakow.pl. exploration (Ref 6). Vianco defined the ultrahigh-temperature solders as those working properly between 573 and $623 \mathrm{~K}$ (Ref 7). Therefore, alloys of similar properties to solders containing $\mathrm{Pb}$ and $\mathrm{Cd}$ are being developed. The literature survey indicates that promising candidate are alloys based on $\mathrm{Zn}-\mathrm{Al}$ eutectic $(654 \mathrm{~K})$ (Ref 8, 9), with additives that lower the melting temperature. Another group of alloys is the Bi-Ag, but due to poor mechanical properties this group is neglected (Ref 10); as well as $\mathrm{Au}-\mathrm{X}$ ( $\mathrm{Sn}, \mathrm{Si}, \mathrm{Ge})$, which because of the high price are only applicable in specific cases (Ref 11). Zn-Al alloys with additions of $\mathrm{Mg}$ and $\mathrm{Ga}$ (Ref 12) have been proposed as a replacement of $\mathrm{Pb}$ solders, due to their thermal conductivity twice as big, and the coefficient of linear expansion smaller than $\mathrm{Pb}-5 \mathrm{Sn}$ (wt\%). These properties are correlated with $\mathrm{Zn}$ which is a major component of the alloys; also the very low price of $\mathrm{Zn}$ is a great advantage of these alloys. Shimizu et al. (Ref 12) also studied the hardness which was one order of magnitude greater than $\mathrm{Pb}-5 \mathrm{Sn}$, as well as wettability at 563$593 \mathrm{~K}$, which turned out to be worse than the $\mathrm{Pb}$-based alloys. $\mathrm{Zn}-\mathrm{Al}-\mathrm{Ga}$ ternary and $\mathrm{Zn}-\mathrm{Al}-\mathrm{Mg}-\mathrm{Ga}$ quaternary alloys were also tested by Rettenmayr et al. (Ref 13), in terms of melting temperature, mechanical properties, and impact of $\mathrm{Ga}$ and $\mathrm{Mg}$ addition on microstructure. To the best of the present authors' knowledge, there are no papers published on thermal properties and wetting behavior of Zn-Al-In alloys. Therefore, the aim of this work is to study temperature properties of alloys based on $\mathrm{Zn}$-Al eutectic with small additions of indium and their wetting behavior on $\mathrm{Cu}$ and $\mathrm{Al}$ substrates. In the present study, melting temperatures, electrical resistivity, thermal expansion and density in the solid state, wetting on $\mathrm{Cu}$ and $\mathrm{Al}$ pads and microstructure of solder/substrate interface were investigated.

\section{Experimental}

Alloys were prepared by melting accurately weighted amounts of high-purity metals (Zn, Al, In 99.999\%). Alloys were melted in a glove-box under protective atmosphere of 
pure argon, with water vapor and oxygen level lower than $1 \mathrm{ppm}$. Such conditions were necessary to limit the oxidation of liquid alloys. The chemical compositions of alloys are presented in Table 1. The alloys were cast into graphite molds and cut into suitable pieces for DSC, density, thermal expansion, and wetting tests.

\subsection{DSC Measurements}

The melting behavior of the solder alloys was investigated with differential scanning calorimetric (DSC) method. The measurements were carried out on samples of about $25 \mathrm{mg}$, with the use of DSC microcalorimeter, with heating and cooling rate of $10 \mathrm{~K} / \mathrm{min}$, under protective atmosphere of high-purity Ar (99.9999\%). The temperature was measured with an accuracy of $1 \mathrm{~K}$.

\subsection{Electrical Resistivity Measurements}

The samples for electrical resistivity studies were prepared by sucking liquid alloys to quartz capillaries with $2 \mathrm{~mm}$ inner diameter and later cut into $150 \mathrm{~mm}$ long pieces. For electrical resistivity measurements the new equipment presented in Fig. 1 was created. This equipment utilizes the 4-point method (Ref 14-16) which is the most commonly used technique for measurement of electrical properties of materials. This method proved to be a convenient tool to measure the resistance of metals. The measurement is performed by four electrical contacts attached to the sample's surface. Two connectors are used to provide current, and the next two for voltage drop measurement. The use of 4-point method eliminates measurement errors resulting from the resistivity of connections (clamps-material). The electrical resistance $\rho$, is determined by charging the current $I$, through the outer contacts and measuring the voltage drop $V$, between the inner contacts, which are placed at a given distance $L$. Errors in determination of the difference in voltage due to thermoelectric power

Table 1 The coefficient of thermal expansion (CTE), density in the solid and molar volume at $293 \mathrm{~K}$, and melting temperatures of $\mathrm{Zn}$-Al-In alloys

\begin{tabular}{lcccc}
\hline Alloy at. \% & CTE, $\mathbf{1 0}^{-\mathbf{6}} \mathbf{K}^{-\mathbf{1}}$ & $\begin{array}{c}\mathbf{\rho}_{\mathbf{M}}, \\
\mathbf{g} / \mathbf{c m}^{\mathbf{3}}\end{array}$ & $\begin{array}{c}\boldsymbol{V}_{\mathbf{M}}, \\
\mathbf{c m}^{\mathbf{3}} / \mathbf{m o l}\end{array}$ & $\begin{array}{c}\text { Melting } \\
\text { range, K}\end{array}$ \\
\hline Zn & 29.87 & 7.133 & 9.18 & $\ldots$ \\
Zn-12Al & 23.97 & 6.575 & 9.26 & 652 \\
Zn-12A1-0.5In & 22.28 & 6.578 & 9.29 & $644-650$ \\
Zn-12Al-1.0In & 28.73 & 6.591 & 9.32 & $643-649$ \\
Zn-12Al-1.5In & 29.32 & 6.602 & 9.33 & $641-645$ \\
\hline
\end{tabular}

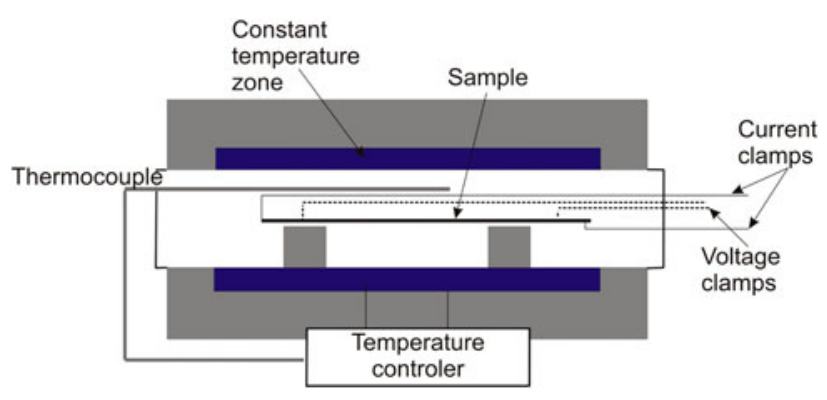

Fig. 1 Sketch of the setup for electrical resistivity measurements between the electrodes can be eliminated with adequate power and the use of the average of the two values measured in both directions. This is enabled with the use of high-quality Keithley 6220 current source $(100 \mathrm{~mA}$ with an accuracy of $10 \mu \mathrm{A})$ coupled with nano-voltmeter Keithley $2182(10 \mathrm{mV}$ range with accuracy $1 \mathrm{nV}$ ) connected together in DELTA mode. The temperature is controlled via a high-class Eurotherm temperature controller (accuracy of $0.1 \mathrm{~K}$ ). Electrical resistance measurements were performed in the temperature range 303$423 \mathrm{~K}$, the samples were cylindrical with a diameter of $2 \mathrm{~mm}$. Collection and processing of data were carried out continuously and in real time. To the equipment for electrical resistivity measurements, holder in which a sample is attached was specially designed. With this solution we are confident that the experiment conditions are the same for all samples. Having known the electrical resistance and the cross-section area of the sample, we can calculate the electrical resistivity.

$\rho=\frac{U}{I} \cdot \frac{1}{l} \cdot \frac{\pi d^{2}}{4}$

where $\rho$ electrical resistivity, $U$ voltage, $I$ current, $l$ measurement length, and $d$ diameter of sample.

The measurements were started at room temperature and subsequently the temperature was raised every $10 \mathrm{~K}$. The sample was kept for $150 \mathrm{~min}$. at each temperature. At constant temperature standard deviation of measured electric resistance value was less than $1 \%$.

\subsection{Density and Thermal Expansion in Solid Measurements}

The measurements of density in the solid state were carried out with the setup utilizing Archimedes method. Distilled water was used as a reference liquid, temperature of measurement was $296 \mathrm{~K}$, and the samples were cylindrical of $5 \mathrm{~mm}$ in diameter and $20 \mathrm{~mm}$ high. The experimental error of measured value of density in solid did not exceed $0.3 \%$. For thermal expansion measurements samples of the same dimensions were used. Thermal expansion measurements were done by TMA setup, under the following conditions of experiment: range of temperature: -50 to $150 \mathrm{~K}$, heating rate: $2 \mathrm{~K} / \mathrm{min}$, gas flow: $20 \mathrm{~mL} / \mathrm{min}$, force exerted on sample: $0.1 \mathrm{mN}$, protective gas: helium.

\subsection{Wetting Measurements}

Measurements of wetting angle were carried out in air at temperature $773 \mathrm{~K}$ using the equipment described in (Ref 17). Before the tests, cylindrical samples of $5 \mathrm{~mm}$ in diameter and $4 \mathrm{~mm}$ high, as well as "as-delivered" $\mathrm{Cu}(99.9 \%)$ and $\mathrm{Al}$ $(99.5 \%)$ substrates of $20 \times 15 \times 0.2 \mathrm{~mm}$ were degreased with acetone. For each type of substrate different flux was used, i.e., for $\mathrm{Cu}$ substrate flux $\mathrm{Al} 700^{\circledR}$ and for $\mathrm{Al}$ substrate flux AFP200 ${ }^{\circledR}$. The samples were kept in the furnace for 1 and 3 min. Because layers of fluxes covering samples were relatively thick it was not possible to measure time dependence of wetting angle. For this reason, the apparent wetting angles reported in this work were determined on solidified samples after cleaning the flux residue with distilled water. The experimental error of wetting angle measurement did not exceed $2^{\circ}$. After measurements of wetting angle, solidified drops were cut on wire saw in the middle of a drop, perpendicular to the plane of the interface, mounted in conductive resin and polished for microstructure characterization. Thin layer of carbon was sputtered on 
samples' surface to protect it against oxidation and improve SEM image quality. EDS analysis was performed at $20 \mathrm{kV}$ and working distance of $10 \mathrm{~mm}$.

\section{Results and Discussion}

\subsection{Melting Temperature}

The results of DSC measurements for Zn-Al-In alloys are presented in Table 1. The study of melting of high-temperature solders shows that the range of applicability of solders is high (up to $623 \mathrm{~K}$ ) and through addition of alloying elements a reduction of melting temperature can be obtained. Too big addition of indium to alloys causes huge differences between melting and solidification temperatures (Ref 12). Also indium is a very expensive metal, given both the facts we decided to study the effect of small addition of indium to $\mathrm{Zn}-\mathrm{Al}$ eutectic. As shown in Table 1, increasing concentration of indium causes slight decrease of melting temperatures. In the case of $\mathrm{Zn}-12 \mathrm{Al}-1.5 \mathrm{In}$ alloy, liquidus temperature is $10 \mathrm{~K}$ lower than eutectic temperature of $\mathrm{Zn}-12 \mathrm{Al}$ alloy. Present results when compared with literature data are higher than those for $\mathrm{Pb}-5.5 \mathrm{Sn}$ alloys (Ref 18) or other alloys based on $\mathrm{Zn}-\mathrm{Al}$ eutectic (Ref 12), but solidus-liquidus gap is smaller.

\subsection{Density in Solid and CTE Results}

The results of density measurements in the solid state $\rho_{M}$ $\left(\mathrm{g} / \mathrm{cm}^{3}\right)$ are presented in Table 1 with the molar volume $V_{\mathrm{M}}$ $\left(\mathrm{cm}^{3} / \mathrm{mol}\right)$ calculated at $296 \mathrm{~K}$. Having experimentally determined coefficient of thermal expansion (CTE) and density in the solid state, we can determine molar volume dependence on temperature. The molar volumes of $\mathrm{Zn}$, eutectic $\mathrm{Zn}-\mathrm{Al}$, and $\mathrm{Zn}$-Al-In alloys as function of temperature are shown in Fig. 2; molar volume of pure $\mathrm{Zn}$ is the lowest, and addition of In to $\mathrm{Zn}-\mathrm{Al}$ eutectic increases $V_{\mathrm{M}}$.

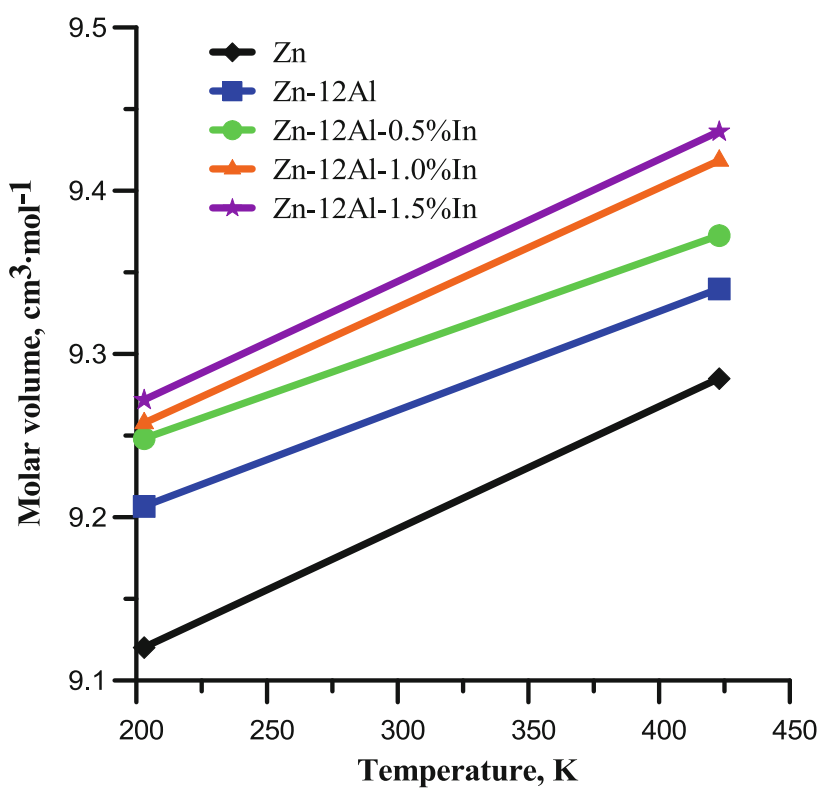

Fig. 2 Molar volume vs. temperature
The results of thermal expansion measurements are shown in Fig. 3 and Table 1. All of the investigated alloys expand linearly with increasing temperature, and CTE of Zn-Al eutectic alloy is $20 \%$ lower than that of pure $\mathrm{Zn}$. Small addition of indium (0.5 at.\%) to $\mathrm{Zn}-\mathrm{Al}$ eutectic causes a small $(7 \%)$ decrease of the CTE, but subsequent additions of indium, i.e., 1.0 and $1.5 \%$ increase the CTE to the values close to that of pure Zn. Large differences in the CTE of solder and substrate can cause problems in the joints during operation at temperature cycles such as cracks at the interface between these materials. The new CTE data of Zn-Al-In alloys are significantly higher than that of copper, which according to (Ref 19), is $17.1 \times 10^{-6} \mathrm{~K}^{-1}$ within the temperature range of $293-573 \mathrm{~K}$. On the other hand, $30.0 \times 10^{-6} \mathrm{~K}^{-1}$ reported for $\mathrm{Pb}-5.5 \mathrm{Sn}$ (wt.\%) solder and $29.0 \times 10^{-6} \mathrm{~K}^{-1}$ reported for $\mathrm{Pb}-10.5 \mathrm{Sn}$ solder (Ref 18) is nearly the same as present results for Zn-12Al-1.0In and Zn-12Al-1.5In alloys (Table 1).

\subsection{Electrical Resistivity}

The results of electrical resistivity measurements indicate that for all of the alloys the electrical resistivity increases with increasing temperature. According to our results, at $303 \mathrm{~K}$ the electrical resistivity of pure $\mathrm{Zn}$ is $7.99 \mu \Omega \mathrm{cm}$, that is higher than $5.68 \mu \Omega \mathrm{cm}$ reported at the same temperature in (Ref 19). One has to be aware, that even for pure metals there is a scatter in literature electrical resistivity data. For example for pure $\mathrm{Zn}$, results as high as $19.0 \mu \Omega \mathrm{cm}$ at $303 \mathrm{~K}$ are reported (Ref 20). For the sake of comparison, electrical resistivity of copper was determined (see Fig. 4) and at $303 \mathrm{~K}$ our result of $2.01 \mu \Omega \mathrm{cm}$ is higher than the reference data reported in (Ref 19, 21), respectively. The difference between our results and reference data for $\mathrm{Cu}$ might be explained by the fact that we used $\mathrm{Cu}$ of low purity (technical purity). Generally, the electrical resistivity of $\mathrm{Zn}$-Al-In alloys is lower than that of Pb-based solders, for example the electrical resistivity of $\mathrm{Sn}-37 \mathrm{~Pb}$ (wt.\%) solder is $14.25 \mu \Omega \mathrm{cm}, \mathrm{Pb}-10.5 \mathrm{Sn}$ is $19.3 \mu \Omega \mathrm{cm}$, and $\mathrm{Pb}-5.5 \mathrm{Sn}$ is

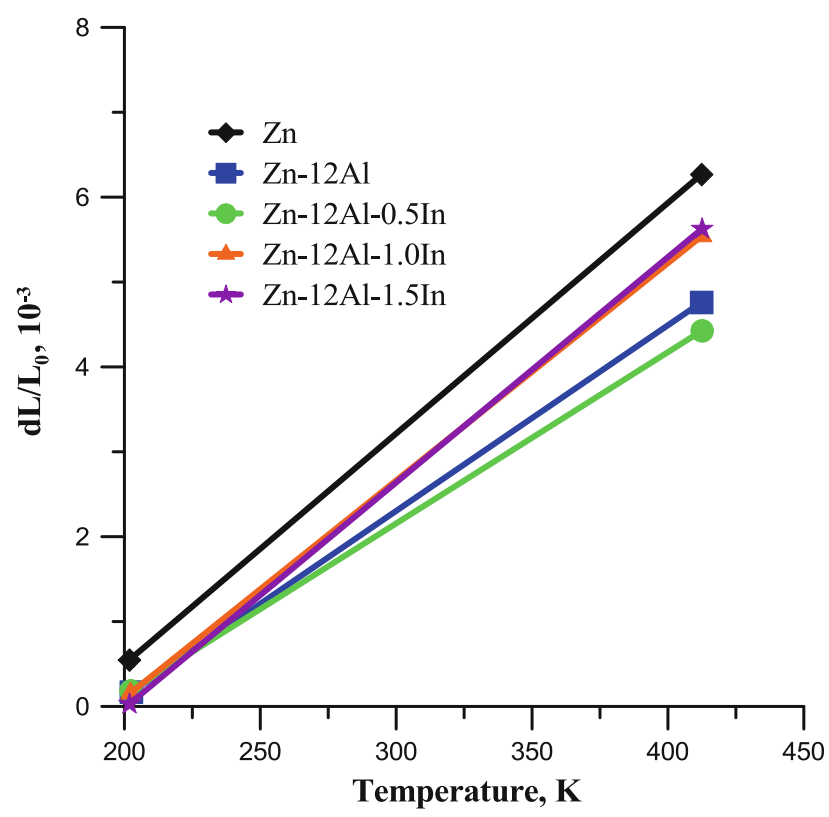

Fig. 3 TMA results of thermal expansion measurements vs. temperature 


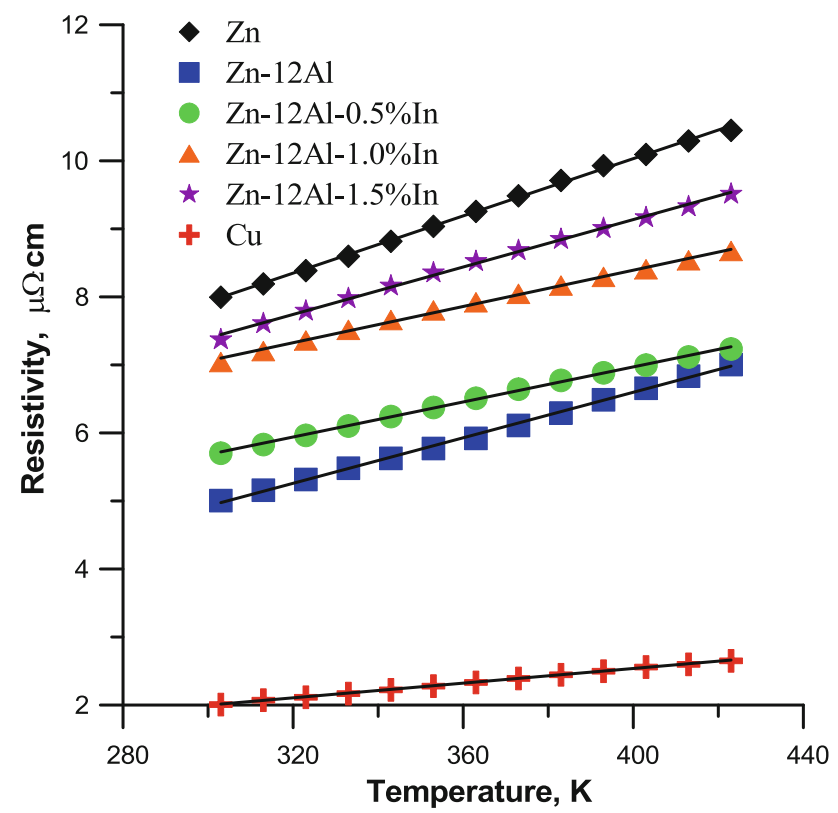

Fig. 4 Electrical resistivity vs. temperature

Table 2 The results of EDS analysis performed on Zn-12Al-0.5In/Al couple at the positions indicated in Fig. 9

\begin{tabular}{lccc}
\hline & \multicolumn{3}{c}{ Element at.\% } \\
\cline { 2 - 4 } & Zn & Al & In \\
\hline 1 & 70.2 & 29.8 & \\
2 & 96.3 & 3.7 & \\
3 & 58.9 & 40.3 & \\
4 & 58.0 & 42.0 & \\
5 & 48.2 & 51.8 & \\
\hline
\end{tabular}

Table 3 The results of EDS analysis performed on $\mathrm{Zn-12Al-1.0In/Al} \mathrm{couple} \mathrm{at} \mathrm{the} \mathrm{positions} \mathrm{indicated} \mathrm{in} \mathrm{Fig.} 10$

\begin{tabular}{lccr}
\hline & \multicolumn{3}{c}{ Element at.\% } \\
\cline { 2 - 4 } & Zn & Al & In \\
\hline 1 & 97.3 & 2.3 & \\
2 & 34.1 & 65 & 0.9 \\
3 & 14.5 & & 85.5 \\
4 & 52.8 & 45.4 & 1.8 \\
\hline
\end{tabular}

Table 4 The results of EDS analysis performed on $\mathrm{Zn-12Al-1.5In/Al} \mathrm{couple} \mathrm{at} \mathrm{the} \mathrm{positions} \mathrm{indicated} \mathrm{in} \mathrm{Fig.} 11$

\begin{tabular}{llcr}
\hline & \multicolumn{3}{c}{ Element at.\% } \\
\cline { 2 - 4 } & Zn & Al & In \\
\hline 1 & 96.3 & 3.7 & \\
2 & 12.4 & & 87.6 \\
3 & 54.4 & 45 & 1.6 \\
4 & 51.4 & 48.6 & \\
5 & 31.8 & 68.2 & \\
\hline
\end{tabular}

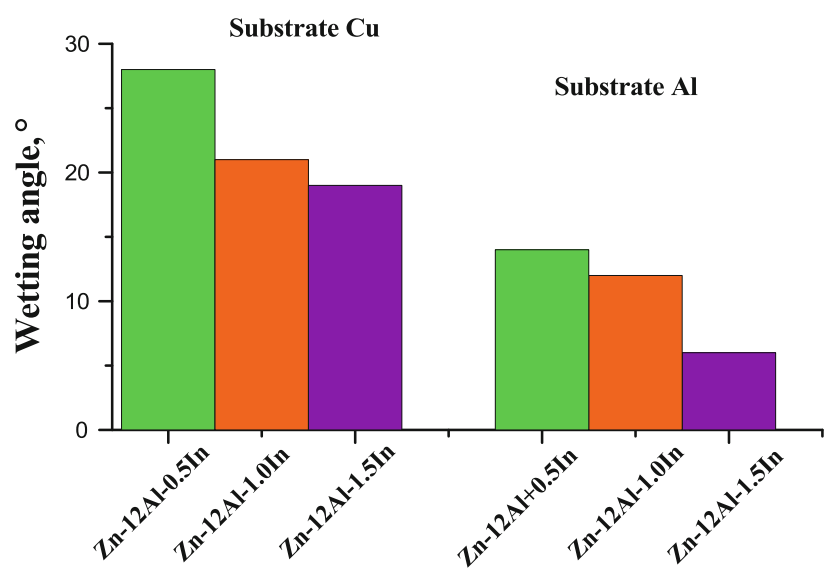

Fig. 5 Wetting angle (apparent) of Zn-Al-In alloys on $\mathrm{Cu}$ and $\mathrm{Al}$ substrates at $773 \mathrm{~K}$

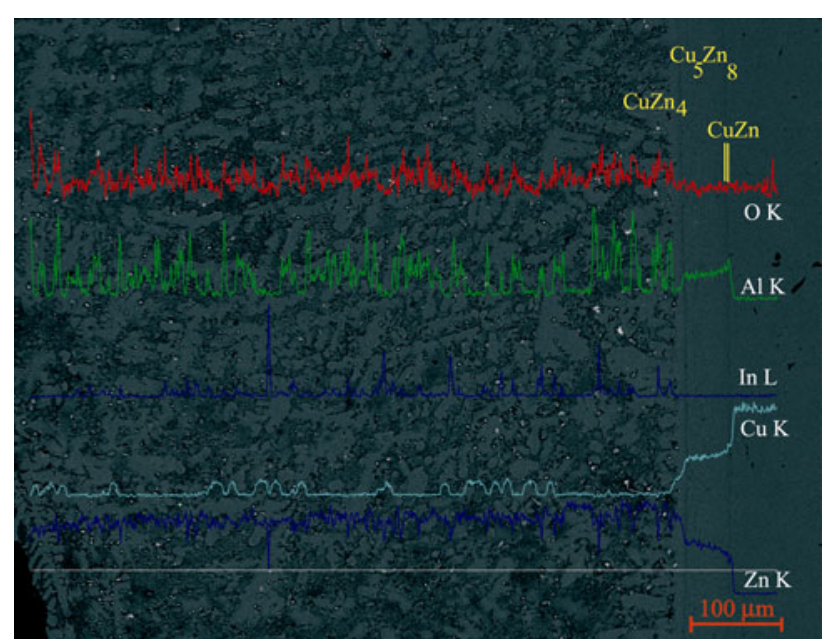

Fig. 6 SEM micrograph of the interface between Sn-12Zn-0.5In alloy and $\mathrm{Cu}$ substrate

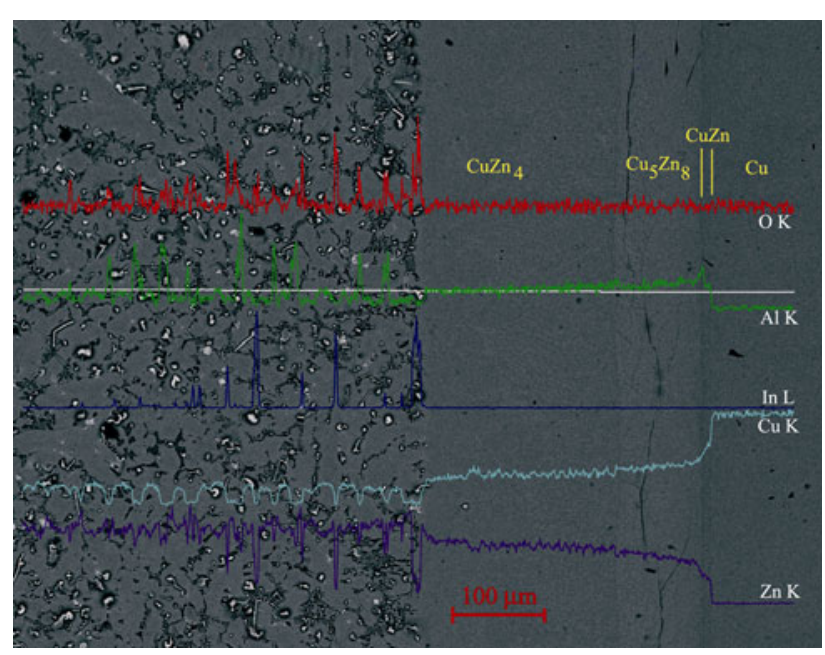

Fig. 7 SEM micrograph of the interface between Sn-12Zn-1.0In alloy and $\mathrm{Cu}$ substrate 
$29 \mu \Omega \mathrm{cm}$ (Ref 18). As we can see in Fig. 4, at low temperatures the electrical resistivity of $\mathrm{Zn}-\mathrm{Al}$ eutectic alloy is about $40 \%$ lower than that of pure $\mathrm{Zn}$. The addition of In to the eutectic alloy causes distinct increase of electrical resistivity. One can see in Fig. 4 that with the addition of $\mathrm{Al}$ to pure $\mathrm{Zn}$ the electrical resistivity is reduced but addition of In to $\mathrm{Zn}-\mathrm{Al}$ eutectic increases resistivity. The same situation was observed by Kang et al. (Ref 6), who studied the electrical resistivity of $\mathrm{Zn}-\mathrm{Al}-\mathrm{Cu}$ alloys and their results of electrical resistivity

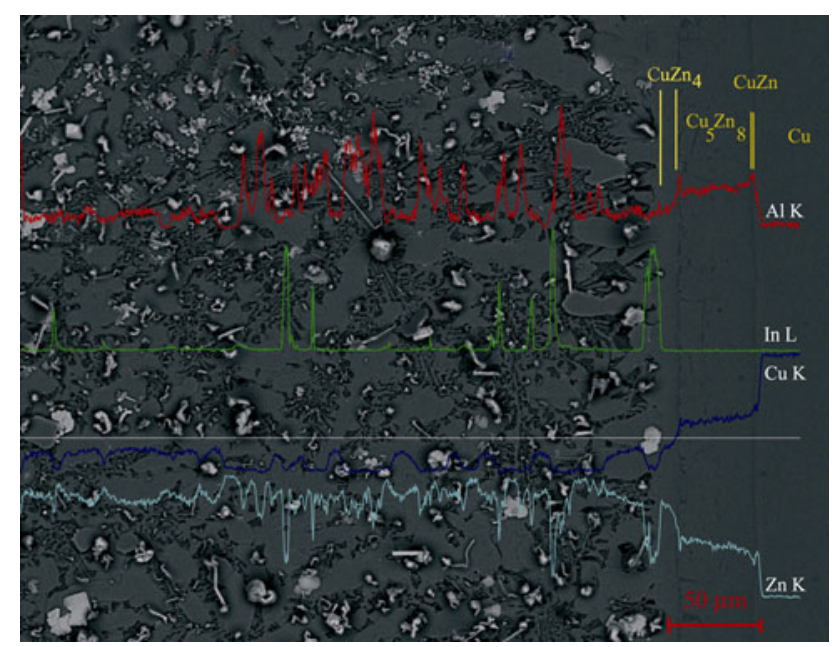

Fig. 8 SEM micrograph of the interface between Sn-12Zn-1.5In alloy and $\mathrm{Cu}$ substrate measurements are in the range from 6.5 to $8.5 \mu \Omega \mathrm{cm}$ at room temperature, depending on addition of $\mathrm{Al}$ and $\mathrm{Cu}$. Their results confirm that the electrical resistivity of $\mathrm{Zn}-\mathrm{Al}$ eutectic is lower than that of $\mathrm{Zn}$, but they also observed that the electrical resistivity increases with increasing concentration of copper. Similarly, we have observed the increase of electrical resistivity with increasing concentration of indium. Based on the results of Kang et al. (Ref 6) for $\mathrm{Zn}-\mathrm{Al}-\mathrm{Cu}$, and our results for $\mathrm{Zn}-\mathrm{Al}-\mathrm{In}$, and the results of EDS analysis of ternary alloys presented in Table 2, 3, and 4, it can be speculated that the increase of electrical resistivity can be attributed to the presence of indiumrich precipitates in the microstructure of Zn-Al-In alloys, whereas $\mathrm{Zn}-\mathrm{Al}$ alloy has simple eutectic microstructure.

\subsection{Wetting}

The result of wetting tests is shown in Fig. 5. Two different "aggressive" fluxes suitable to each substrate were used for wetting tests. The apparent wetting angles on copper substrate are higher than the wetting angles on aluminum, for respective compositions. The increasing concentration of In in $\mathrm{Zn}$-Al-In alloys decreases the wetting angle on $\mathrm{Cu}$ and $\mathrm{Al}$ substrates. Wetting angles on $\mathrm{Cu}$ and $\mathrm{Al}$ substrates are lower than $30^{\circ}$, which indicates very good wetting according to the classification of wetting by Klein-Wassink (Ref 22).

Figures 6,7 , and 8 present the microstructure of crosssectioned $\mathrm{Zn}$-Al-In / Cu couples, with the results of line scan EDS analysis imposed on. Line scans of $\mathrm{Zn}$-Al-In alloys on $\mathrm{Cu}$ substrate show that the $\mathrm{In}$ and $\mathrm{Cu}$ in solders are in the form of precipitates. At the solder/substrate interface three interlayers can be distinguished. Starting from the substrate these are:
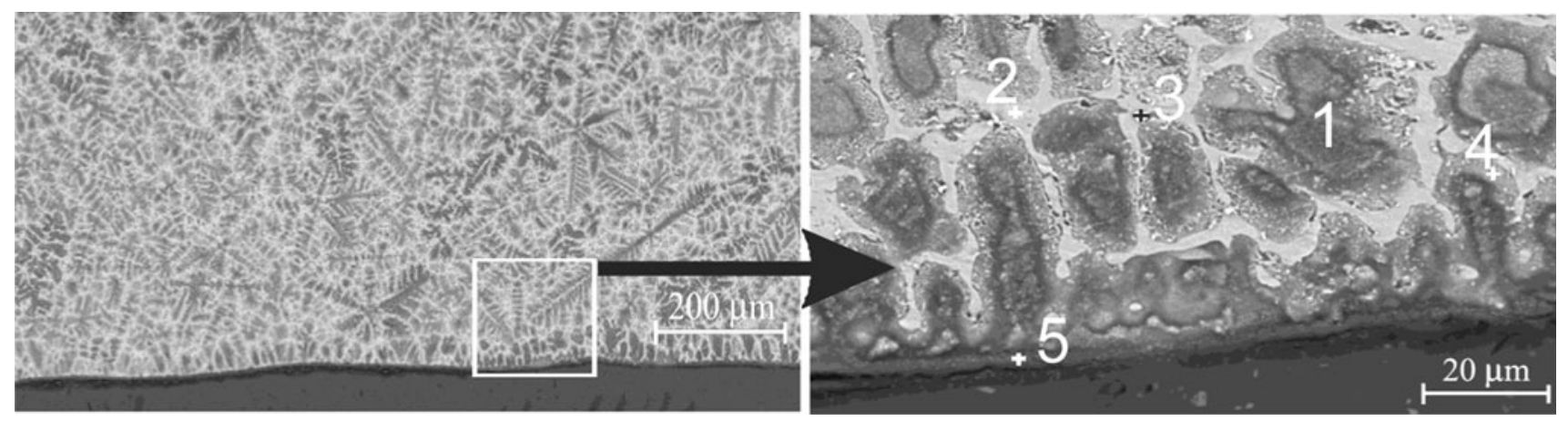

Fig. 9 SEM micrograph of the interface between Sn-12Zn-0.5In alloy and Al substrate
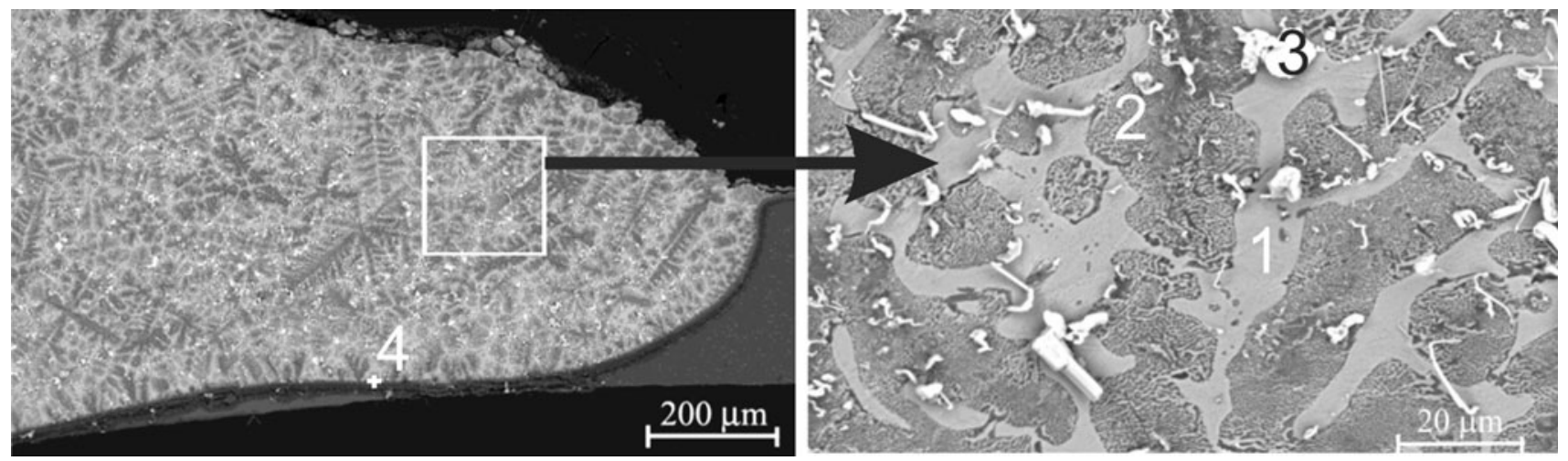

Fig. 10 SEM micrograph of the interface between Sn-12Zn-1.0In alloy and Al substrate 


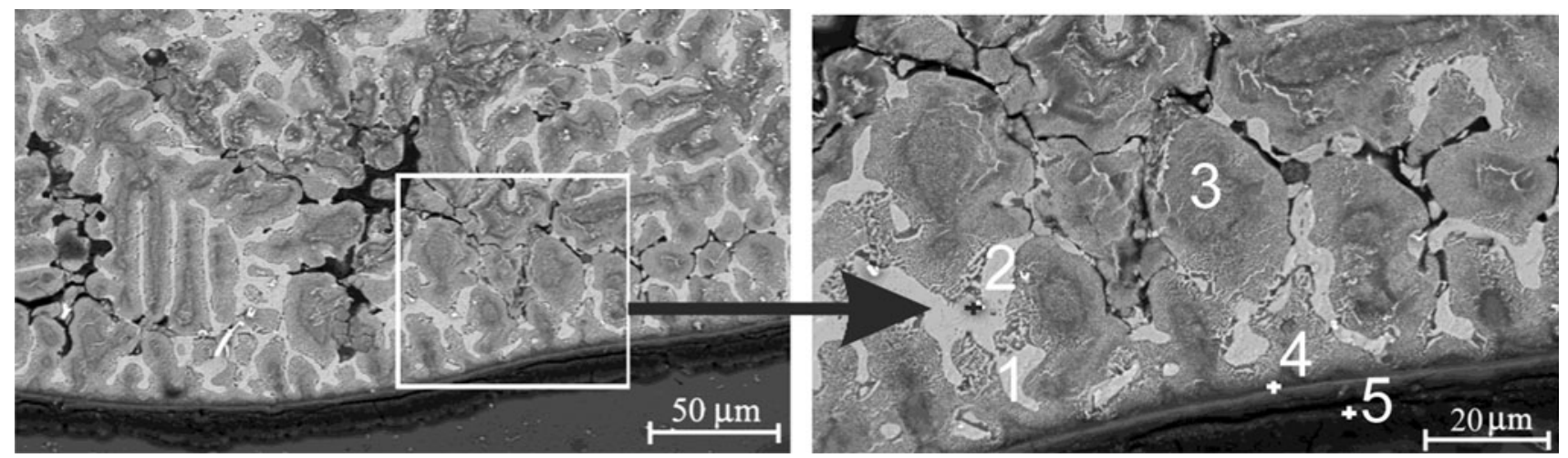

Fig. 11 SEM micrograph of the interface between Sn-12Zn-1.5In alloy and Al substrate

$\mathrm{ZnCu}, \mathrm{Cu}_{5} \mathrm{Zn}_{8}$, and $\mathrm{CuZn}_{4}$. Our results are in agreement with the results of Takaku et al. (Ref 23), who observed formation of the same layers at the $\mathrm{Zn}-\mathrm{Al}$ solder/Cu substrate interface. However, we can see that in the case of $\mathrm{Zn}-12 \mathrm{Al}-1.0 \mathrm{In}$ alloy the thickness of layers is bigger. The reason is that the time for which the sample was kept in the furnace was three times longer than in the case of other Zn-Al-In alloys. This is also in agreement with the work of Takaku (Ref 23), who investigated the kinetics of growth of $\mathrm{CuZn}_{4}$ phase and observed linear relationship between the sample residence time in the furnace and the growth of the phase. The micrographs presented in Fig. 9, 10, and 11 show the microstructures of Zn-Al-In alloys on Al substrate. During the soldering process at $773 \mathrm{~K}$, using AFP200 flux, the Al substrate was dissolved, as shown in Fig. 10. The results of EDS measurements of the composition in points shown in Fig. 9, 10, and 11 are listed in Table 2, 3, and 4 , respectively. In the $\mathrm{Zn}-12 \mathrm{Al}-0.5 \mathrm{In}$ solder/aluminum cross-section (Fig. 9), the interlayer contains 48.2 at.\% of $\mathrm{Zn}$. The $\mathrm{Al}$ is present in the solder in the form of Al-rich precipitates (Table 2, composition 1). At the drop/substrate interface layers rich in $\mathrm{Zn}$ and $\mathrm{Al}$ are formed. The EDS analysis reveals diffusion of aluminum into the drops (Table 3, point 2). According to phase diagram of $\mathrm{Zn}-\mathrm{Al}$ system (Ref 24), the concentration of $\mathrm{Al}$ will be increasing in alloy. The dissolution of the Al substrate in the Zn-Al-In alloy can be observed in all microstructures (Fig. 9, 10, 11), which is confirmed by EDS analysis results (Table $2,3,4$ ). As a result concentration of $\mathrm{Al}$ in solidified solder samples is higher than nominal solder composition. Higher Al content in the alloy should reduce the electrical resistance and increase the mechanical properties, as has been shown by Kang et al. (Ref 6).

\section{Conclusion}

Thermal properties and wetting behavior of Zn-Al-In alloys were studied. It was found that the addition of indium reduces the melting temperature of the $\mathrm{Zn}-\mathrm{Al}$ solder. The results of the electrical resistivity measurements show that the addition of indium to $\mathrm{Zn}-\mathrm{Al}$ eutectic results in higher resistivity of ternary alloys compared to $\mathrm{Zn}-\mathrm{Al}$ eutectic. The studied alloys expand linearly with increasing temperature over the whole temperature range. CTE for $\mathrm{Zn}-12 \mathrm{Al}-0.5 \mathrm{In}$ alloy is lower compared to $\mathrm{Zn}-\mathrm{Al}$ eutectic alloy, while CTE for $\mathrm{Zn}-12 \mathrm{Al}-1.0 \mathrm{In}$ and
$\mathrm{Zn}-12 \mathrm{Al}-1.5 \mathrm{In}$ is higher. The increasing concentration of indium in alloys, which is present in small precipitates, reduces the apparent wetting angle of the $\mathrm{Zn}$-Al-In solders on the $\mathrm{Cu}$ and $\mathrm{Al}$ substrates. On $\mathrm{Cu}$ substrate interlayers are formed on solder/substrate interface, and their composition matches the intermetallics from the $\mathrm{Cu}-\mathrm{Zn}$ system. On the other hand, in the case of $\mathrm{Zn}-\mathrm{Al}-\mathrm{In} / \mathrm{Al}$ couples dissolution of aluminum substrate is observed. The results of EDS analysis indicate that $\mathrm{Cu}$ diffuses from the substrate and is present in the drop in the form of small precipitates.

\section{Acknowledgments}

This work was financed under the framework of the project POIG.01.01.02-00-015/09, co-funded by the European Regional Development Fund (ERDF) and the Government of Poland under the Innovative Economy Program. The authors are grateful to Dr A. Sypien for her help with EDS analysis.

\section{Open Access}

This article is distributed under the terms of the Creative Commons Attribution License which permits any use, distribution, and reproduction in any medium, provided the original author(s) and the source are credited.

\section{References}

1. K. Suganuma, Advances in Lead-Free Electronics Soldering, Curr. Opin. Solid State Mater. Sci., 2001, 5(1), p 55-64

2. S. Mhiaoui, F. Sar, and J.G. Gasser, Electrical and Thermal Conductivities and Thermopower of some Lead Free Solders (LFS) in the Liquid and Solid State, J. Non-Cryst. Solids, 2007, 353, p 3628-3632

3. K. Seelig, D. Suraski, Lead-Free Soldering Guide, www.aimsolder.com, 2003

4. T. Gancarz, Z. Moser, W. Gạsior, J. Pstruś, and H. Henein, A Comparison of Surface Tension, Viscosity and Density of $\mathrm{Sn}$ and Sn-Ag Alloys Using Different Measurement Techniques, Int. J. Thermophys., 2011, 32(6), p 1210-1233

5. T. Gancarz and W. Gạsior, EMF Study of the Liquid Sb-Sn-Zn Alloys, J. Phase Equilib. Diff., 2011, 32(5), p 398-406

6. N. Kang, H.S. Na, S.J. Kim, and C.Y. Kang, Alloy Design of Zn-Al$\mathrm{Cu}$ Solder for Ultra High Temperatures, J. Alloy. Compd., 2009, 467, p 246-250

7. P.T. Vianco, Solder Technology for Ultrahigh Temperatures, Weld. J., 2002, 81(10), p 51-54

8. J. Spriestersbach, J. Wisniewsk, and F. Prenger, Method for Insert Gas Welding or Insert Gas Soldering of Workpieces Comprising Identical 
or Different Metals or Metal Alloys by Means of an Additional Zn/Al Metal, US Patent 7,329,828 B2, 12 Feb 2008

9. M. Nobumasa and N. Shuichi, Japan Patent 2006-320913, 2006

10. Y. Yamada, Y. Takaku, Y. Yagi, I. Nakagawa, T. Atsumi, M. Shirai, I. Ohnuma, and K. Ishida, Reliability of Wire-Bonding and Solder Joint for High Temperature Operation of Power Semiconductor Device, Microelectron. Reliab., 2007, 47(12), p 2147-2151

11. K. Suganuma, S.-J. Kim, and K.-S. Kim, High-Temperature Lead-Free Solders: Properties and Possibilities, J. Miner. Met. Mater. Soc., 2009, 61(1), p 64-71

12. T. Shimizu, H. Ishikawa, I. Ohnuma, and K. Ishida, Zn-AI-Mg-Ga Alloys as Pb-Free Solder for Die-Attaching Use, J. Electron. Mater. 1999, 28(11), p 1172-1175

13. M. Rettenmayr, P. Lambracht, B. Kempf, and C. Tschudin, Zn-Al Based Alloys as Pb-Free Solders for Die Attach, J. Electron. Mater. 2002, 31(4), p 278-285

14. F.M. Smits, Measurement of Sheet Resistivities with the Four Probe, Bell Syst. Tech. J., 1958, 37, p 711-718

15. F. Abd El-Salam, A.M. Ibraheim, A.H. Ammar, and A.Y. Morsy, The Temperature Dependence of the Electrical Resistivity of Al-Zn Alloy Thin Films, Vacuum, 1995, 46(11), p 1299-1303
16. R. Brandt and G. Neuer, Electrical Resistivity and Thermal Conductivity of Pure Aluminum and Aluminum Alloys up to and above the Melting Temperature, Int. J. Thermophys., 2007, 28(5), p 14291446

17. P. Fima, W. Gasior, A. Sypien, and Z. Moser, Wetting of $\mathrm{Cu}$ by Bi-Ag Based Alloys with Sn and Zn Additions, J. Mater. Sci., 2010, 45(16), p 4339-4344

18. www.matweb.com

19. W.F. Gale and T.C. Totemeier, Ed.,Smithells Metals Reference Book, Elsevier, Butterworth-Heinemann, Oxford, 2004, p 19-21

20. M. Ari, B. Saatçi, M. Gündüz, M. Payveren, and S. Durmuş, Thermoelectrical Characterization of $\mathrm{Sn}-\mathrm{Zn}$ Alloys, Mater. Charact., 2008, 59, p 757-763

21. IEC 60468 standard, International Standard of Resistance for Copper

22. R.J. Klein-Wassink, Soldering in Electronics, 2nd ed., Electochemical Publications, Ayr, Scotland, 1984

23. Y. Takaku, L. Felicia, I. Ohnuma, R. Kainuma, and K. Ishida, Interfacial Reaction Between $\mathrm{Cu}$ Substrates and $\mathrm{Zn}-\mathrm{Al}$ Base HighTemperature Pb-Free Solders, J. Electron. Mater, 2008, 37(3), p 314 323

24. ASM Metals Handbook, Alloy Phase Diagrams, Vol 3, 1992 